\title{
Analysis of High Torque and Power Densities Outer-Rotor PMFSM with DC Excitation Coil for In-Wheel Direct Drive
}

\author{
M. Z. Ahmad ${ }^{1,2 *}$, E. Sulaiman ${ }^{1,2}$, and T. Kosaka ${ }^{3}$ \\ ${ }^{1}$ Faculty of Electrical and Electronic Engineering, Universiti Tun Hussein Onn Malaysia, Johor Malaysia \\ ${ }^{2}$ Reseacrh Center for Applied Electromagnetics, Universiti Tun Hussein Onn Malaysia, Johor Malaysia \\ ${ }^{3}$ Dept. of Electrical and Computer Engineering, Nagoya Institute of Technology, Nagoya, Japan
}

(Received 26 March 2015, Received in final form 6 August 2015, Accepted 19 August 2015)

\begin{abstract}
In recent years, flux switching machines (FSMs) have been an attractive research topic owing to their tremendous advantages of robust rotor structure, high torque, and high power capability suitable for intensive applications. However, most of the investigations are focusing on the inner-rotor structure, which is incongruous for direct drive applications. In this study, high torque and power densities of a new 12S-14P outer-rotor permanent magnet (PM) FSM with a DC excitation coil was investigated based on two-dimensional finite element analysis for in-wheel direct drive electric vehicle (EV). Based on some design restrictions and specifications, design refinements were conducted on the original design machine by using the deterministic optimization approach. With only $1.0 \mathrm{~kg}$ PM, the final design machine achieved the maximum torque and power densities of $12.4 \mathrm{Nm} / \mathrm{kg}$ and $5.93 \mathrm{~kW} / \mathrm{kg}$, respectively, slightly better than the inner-rotor HEFSM and interior PM synchronous machine design for $\mathrm{EV}$.
\end{abstract}

Keywords : dual excitation flux, outer-rotor, flux switching machine, Direct drive

\section{Introduction}

In the $21^{\text {st }}$ century, global warming is one of the major issues discussed all over the world by scientists and government agencies. The major factor that contributes to the global warming is the greenhouse effect, because of the human activities, heat by solar radiation, and geomagnetic variation [1]. As reported previously [2], the burning of fossil fuels is one of the main contributors to the global warming issue by means of conventional internal combustion engine (ICE) vehicles. Because the price of fossil fuel is increasing year by year, lots of researcher and industries are looking for electric vehicles (EVs) as the most possible solution for transportation [3]. Thus, the commercialization of EV may dramatically decrease the air pollution and will meet the world energy strategy to seek for an energy future that would be secure, efficient, and environmentally sound [4].

In general, the propulsion system for conventional EVs comprises batteries, electric motors with drives, and trans-

CThe Korean Magnetics Society. All rights reserved.

*Corresponding author: Tel: +6019-7886463

Fax:+607-4536060, e-mail: zarafi@uthm.edu.my mission gears to the wheels. This configuration leads to torque and power loss in the transmission system, thus decreasing the electric motor's efficiency. Moreover, it consumes a lot of space to locate the transmission and gearing system in vehicle's cabin that increase the total vehicle weight. Therefore, in-wheel direct drive motor is an alternative model for $\mathrm{EV}$, where the transmission system comprising gearing, belting, and mechanical system in the conventional EV can be eliminated. Thus, the transmission losses are minimized, and the operational efficiency and reliability are improved [5]. Moreover, more batteries can be installed in the space that would be occupied by the transmission system, which will help to increase the driving range per charge. In contrast, because of the elimination of gears, the system needs to produce the total torque directly into the wheel shaft with higher torque and power density as compared to that in the conventional EV [6, 7].

Electric motors with a high torque density capability must be used for heavy applications such as in aerospace and automotive area [8]. Previously, PM brushless machines are widely used for these heavy applications owing to their advantages of high torque density, high power density, wide speed range, wide constant power, and high 
efficiency capabilities $[9,10]$. Nevertheless, because the main flux source of PMs is located on the rotor, the machines suffer from the demagnetization effects and eddy current loss in the rotor. Moreover, the difficulty to remove heat from the rotating part is among the major issues of this type of electric machine.

Almost a decade, flux-switching motors (FSMs) have been an attractive research topic owing to their several advantages of higher torque density and efficiency. With all the active components such as PM, DC field excitation coil (DC FEC), and armature coil located on the stator, the machine in which only a single piece of rotor iron is used becomes extremely robust. Various applications of FSM have been reported, ranging from wind power generation, automotive, aerospace, power tools and etc [11-14]. In general, FSMs can be classified into three groups, namely PM FSMs, hybrid excitation (HE) FSMs, and field excitation (FE) FSMs. Both the PMFSMs and FEFSMs have only single excitation flux source which either comes from the PM or FE coil, respectively, whereas in HEFSM there are two magnetic flux sources, which come from PMs and FECs [15].

However, to date, most of the designed FSMs are mainly focused on inner-rotor configurations $[16,19]$ and earliest report on the outer-rotor PMFSM was published in 2010 where the machine target is to be applied for light traction EV applications [20, 21]. Nonetheless, with a single magnetic flux source of a constant PM, it may also suffer from the demagnetization effect and uncontrollable flux.

This study presents an investigation and optimization study of 12S-14P outer-rotor PMFSM with DC FEC to meet the requirement of in-wheel direct drive EV. In this machine, the presence of FEC makes the machine more attractive especially for the modulating flux of PM. The existence of FEC provides an extra advantage to the machine, acting as the secondary flux source to improve the maximum torque and power capabilities, because of variable flux control capability. Initially, the feasibility study of the proposed machine was reported as discussed [22]. However, based on initial analysis using 2D-FEA, the proposed machines have several drawbacks that prevent them to achieve maximum performances especially at maximum current densities. To improve the design drawbacks, some design refinements and optimization were conducted by the deterministic optimization approach. The outline of this study is divided into the following sections:

Section 2. Principle operation of the proposed machine

Section 3 Investigation of the original design machine based on 2D-FEA of 12S-14P outer-rotor PMFSM with the DC FEC configuration

Section 4. Methods of obtaining maximum performances based on FEA

Section 5. The final design and the optimal performances of the machine

Section 6. Conclusions

\section{Principle Operation of Outer-Rotor PMFSM with DC Excitation Coil}

The term "flux switching" was introduced to explain the fact that the excitation flux linkage switches its polarity by following the motion of the salient pole rotor. For details, the operating principle of the proposed outer-rotor PMFSM with DC FEC is illustrated in Fig. 1 where the upper part is the salient rotor core and the lower part represents the stator body comprising PM, armature winding, and FEC winding. The excitation flux of the PM and FEC is indicated by red and blue lines, respectively. When the polarity and direction of both the flux of PM and FEC are the same as shown in Figs. 1(a) and 1(b), both fluxes are combined and moved together into the rotor, hence producing more flux called as the hybrid excitation flux. Furthermore, Figs. 1(c) and 1(d) show that the polarity of FEC is in the reverse direction and only the flux of PM flows into the rotor, whilst the flux of FEC just move around the FEC slot area, thus bring out less flux excitation. The flux does not rotate, but shifts clockwise and counter-clockwise with each armature current reversal. Therefore, the flux of PM can be easily controlled by DC FEC with variable flux control capabilities even under field weakening and field strengthening

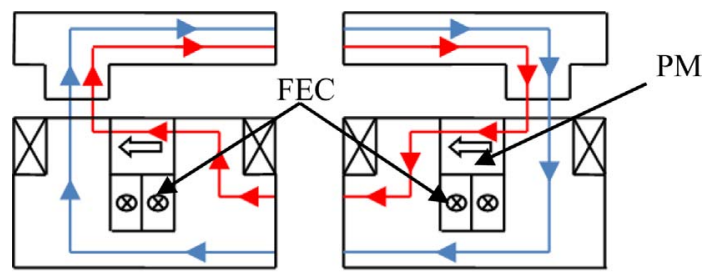

(a)

(b)

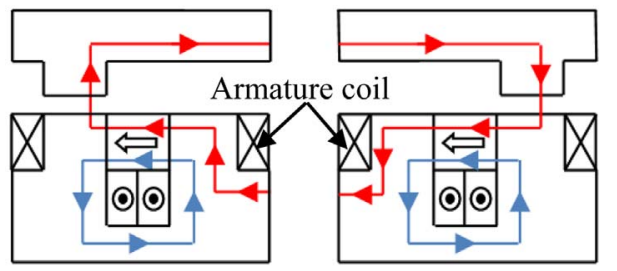

(c)

(d)

Fig. 1. (Color online) Principle operation of outer-rotor PMFSM with DC excitation coil; maximum excitation (a) $\theta_{\mathrm{e}}=$ $0^{\circ}$, (b) $\theta_{\mathrm{e}}=180^{\circ}$; minimum excitation (c) $\theta_{\mathrm{e}}=0^{\circ}$, (d) $\theta_{\mathrm{e}}=180^{\circ}$. 
conditions.

\section{Original Design Performances Based on 2D-FEA}

\subsection{Original Design Structure}

Initially, the proposed 12S-14P outer-rotor PMFSM with DC FEC was designed using the commercial FEA package, JMAG-Designer V.13 software. This software is used as the 2D finite element solver throughout the design studies. The original structure of the proposed machine is illustrated in Fig. 2, and the number of turns of the armature coil and FEC were investigated by Eq. (1).

$$
N_{a}=\sqrt{\frac{\alpha_{a} R_{a} S_{a}}{4 \rho L_{a-a v e}}} \text { and } N_{e}=\sqrt{\frac{\alpha_{e} R_{e} S_{e}}{4 \rho L_{e-a v e}}}
$$

where subscripts ' $a$ ' and ' $e$ ' indicate armature coil and FEC components, respectively, $N$ is the number of turns of coil winding, $\alpha$ is the filling factor, $R$ is the coil resistance $(\Omega), S$ is the coil slot area $\left(\mathrm{mm}^{2}\right)$, and $L$ is the average coil length $(\mathrm{mm})$. Furthermore, the current density of armature coil $\left(J_{a}\right)$ and FEC $\left(J_{e}\right)$ are determined by Eq. (2). In this design, the material used for the conductor is SWG-24 copper with a diameter of $1 \mathrm{~mm}$.

$$
J_{a}=\frac{I_{a} N_{a}}{\alpha_{a} S_{a}} \text { and } J_{e}=\frac{I_{e} N_{e}}{\alpha_{e} S_{e}}
$$

The proposed machine comprises 24 stator teeth with alternate DC FEC, alternate PM flux direction, and counter clockwise armature coil slots around the stator body. The material used for the PM is NEOMAX-35AH whose residual flux density and coercive force at $20^{\circ} \mathrm{C}$

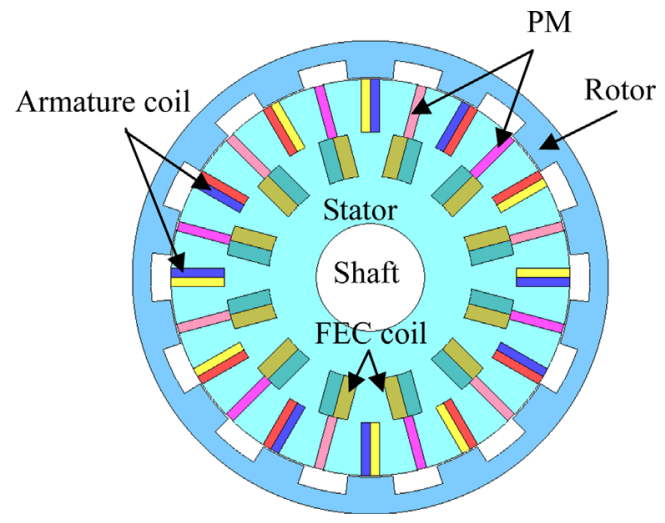

Fig. 2. (Color online) Cross-sectional view of the original outer-rotor PMFSM with DC FEC.

are $1.2 \mathrm{~T}$ and $932 \mathrm{kA} / \mathrm{km}$, respectively, and electromagnetic steel $35 \mathrm{H} 210$ was used for the rotor and stator core.

\subsection{Design Restrictions and Specifications}

The design restrictions and specifications of the proposed outer-rotor PMFSM with DC FEC are based on the inner-rotor HEFSM and IPMSM designed for HEV listed in Table 1 [19]. In this design, the target performances of the maximum torque and power were expected to be $>333 \mathrm{Nm}$ and $123 \mathrm{~kW}$, respectively, under the maximum inverter current, voltage, armature current density, and FEC current density ratings of $360 \mathrm{~A}_{\mathrm{rms}}, 650 \mathrm{~V}, 30 \mathrm{~A}_{\text {rms }} /$ $\mathrm{mm}^{2}$, and $30 \mathrm{~A} / \mathrm{mm}^{2}$, respectively. The target weight of the proposed motor was initially set to be at least $30 \mathrm{~kg}$, which is $5 \mathrm{~kg}$ less compared to that of IPMSM. Therefore, it is expected that the proposed machine can achieve the maximum power and torque density of $11.1 \mathrm{Nm} / \mathrm{kg}$

Table 1. Design restrictions and specifications of the outer-rotor PMFSM with DC FEC.

\begin{tabular}{lcc}
\multicolumn{1}{c}{ Descriptions } & IPMSM & $\begin{array}{c}\text { Target Outer-Rotor } \\
\text { PMFSM with DC FEC }\end{array}$ \\
\hline Max. DC-bus voltage inverter $(\mathrm{V})$ & 650 & 650 \\
Max. inverter current $\left(\mathrm{A}_{\mathrm{rms}}\right)$ & 360 & 360 \\
Max. current density in armature coil, $\mathrm{J}_{\mathrm{a}}\left(\mathrm{A}_{\mathrm{rms}} / \mathrm{mm}^{2}\right)$ & $\mathrm{Conf}$ & 30 \\
Max. current density in FEC, $\mathrm{J}_{\mathrm{e}}\left(\mathrm{A} / \mathrm{mm}^{2}\right)$ & $\mathrm{NA}$ & 30 \\
Motor radius $(\mathrm{mm})$ & 132 & 132 \\
Motor stack length $(\mathrm{mm})$ & 70 & 70 \\
Shaft/Inner motor radius $(\mathrm{mm})$ & 30 & 30 \\
Air gap length $(\mathrm{mm})$ & 0.8 & 0.8 \\
PM weight $(\mathrm{kg})$ & 1.1 & 1.0 \\
Total weight $(\mathrm{kg})$ & 35 & $<30$ \\
Maximum torque $(\mathrm{Nm})$ & 333 & $>333$ \\
Maximum power $(\mathrm{kW})$ & 123 & $>123$ \\
Maximum torque density $(\mathrm{Nm} / \mathrm{kg})$ & 9.51 & 11.1 \\
Maximum power density $(\mathrm{kW} / \mathrm{kg})$ & 3.51 & 4.1 \\
\hline
\end{tabular}


and $4.1 \mathrm{~kW} / \mathrm{kg}$, respectively. In contrast, the weight of the machine was calculated based on the density of each material including PM, iron core, and copper conductor. In this design, the PM weight was set to $1.0 \mathrm{~kg}$ to reduce the total weight and manufacturing cost of the machine, whereas the weights of the iron core and copper conductor were calculated by Eqs. (3) and (4), respectively.

$$
\begin{aligned}
& W_{\text {core }}=V_{\text {core }} \times D_{\text {core }} \\
& W_{c u}=\left(V_{\text {coil-slot }}+V_{\text {coil-end }}\right) \times D_{c u}
\end{aligned}
$$

where $W_{\text {core }}, V_{\text {core }}$, and $D_{\text {core }}$ are the weight, volume, and density material of the iron core used in this design; similarly, $W_{c u}, V_{\text {coil-slot }}, V_{\text {coil-end, }}$ and $D_{c u}$ are the weight, volume of the coil slot, volume of the coil end, and density of copper used for the coil windings, respectively.

\subsection{Initial Performances on Original Design Machine}

Under no load condition, the cogging torque of the proposed machine is shown in Fig. 3. The analysis was performed for one electric cycle at $25.71^{\circ}$ of rotor position. The graph clearly shows that six cycles cogging torque with the maximum peak-to-peak of $7.99 \mathrm{Nm}$ was produced. The peak-to-peak cogging torque is within the acceptable range as compared to the maximum target torque. The peak-to-peak cogging torque was expected to be reduced by improving the initial design machine.

Furthermore, the induced voltages of various DC FEC current densities at a rated speed of $3000 \mathrm{r} / \mathrm{min}$ are plotted as shown in Fig. 4. The induced voltage at PM only has the lowest magnitude of $\sim 81.58 \mathrm{~V}$, whereas the highest magnitude recorded was $319.68 \mathrm{~V}$ at a DC FEC current density of $15 \mathrm{~A} / \mathrm{mm}^{2}$. At no DC FEC current density, the graph is almost sinusoidal, but when the DC FEC current density is further increased, the induced voltage becomes distorted because some of the fluxes from PM are cancelled by the flux generated from DC FEC.

The flux linkages of the proposed machine at various

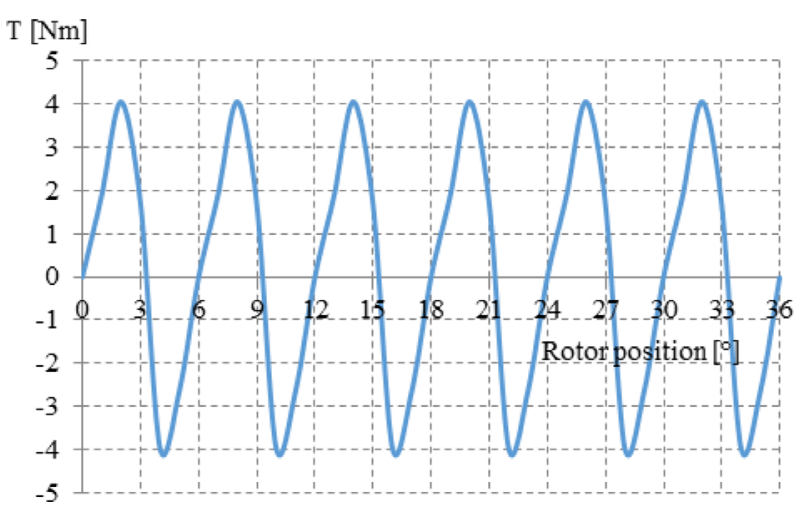

Fig. 3. (Color online) Cogging torque.

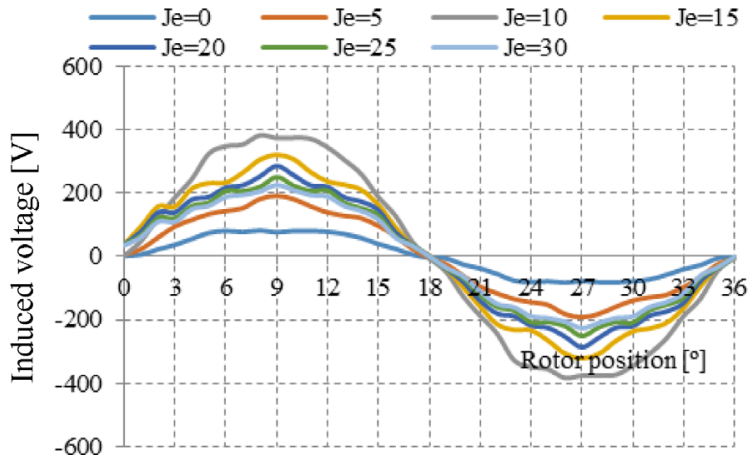

Fig. 4. (Color online) Back-emf at $3000 \mathrm{r} / \mathrm{min}$.

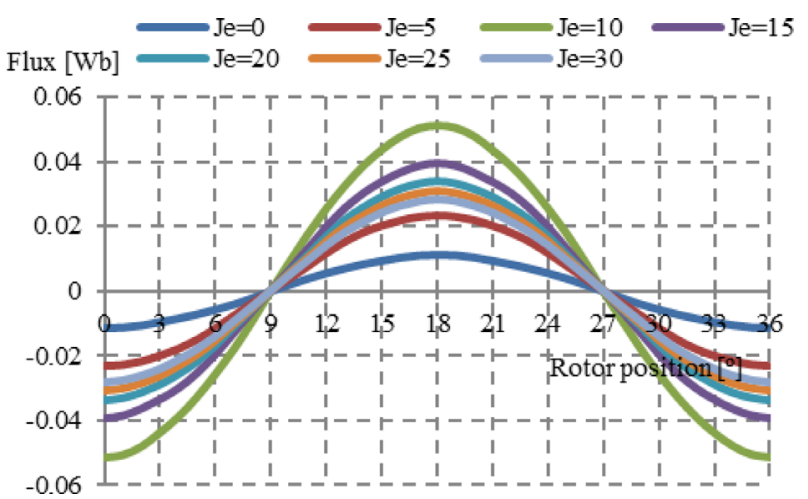

Fig. 5. (Color online) Flux linkage at various DC FEC current densities.

DC FEC current densities are shown in Fig. 5. With increasing DC FEC current density, $J_{e}$, the flux linkage increased and reached to the maximum when $J_{e}$ was set to $10 \mathrm{~A} / \mathrm{mm}^{2}$. The maximum flux linkage at this condition was $\sim 0.051 \mathrm{~Wb}$, which increased more than thrice when compared to the flux linkage coming from the PM only. With further increase in the $J_{e}$, the flux linkage starts to decrease and finally when the $J_{e}$ was set to a maximum of $30 \mathrm{~A} / \mathrm{mm}^{2}$, the magnitude of flux linkage was $\sim 0.028 \mathrm{~Wb}$. This phenomenon is expected because of the flux saturation when $J_{e}>10 \mathrm{~A} / \mathrm{mm}^{2}$ is injected to the system. Thus, this analysis has proved that the additional DC FEC can improve the flux generated from the PM to provide higher torque and offers variable flux control capability.

Further investigations on the flux distribution at several current densities to identify the root cause of the performance reduction were conducted, as shown in Fig. 6. The analysis was performed at a constant armature current density of $30 \mathrm{~A}_{\mathrm{rms}} / \mathrm{mm}^{2}$ at the DC FEC current densities of $0,10,20$, and $30 \mathrm{~A} / \mathrm{mm}^{2}$. From the results, at a $J_{e}$ of 0 $\mathrm{A} / \mathrm{mm}^{2}$, the flux flows easily from the stator to the rotor and returns back to the stator through the adjacent rotor pole making a complete cycle of PM flux. However, at the some portion, there is flux saturation especially on the 
region circled by the red color in Fig. 6(a). When a low $J_{e}$ of $10 \mathrm{~A} / \mathrm{mm}^{2}$ is applied to the system, more flux is generated and obviously the flux saturation decreased because of the flux cancellation between the flux of PM and flux

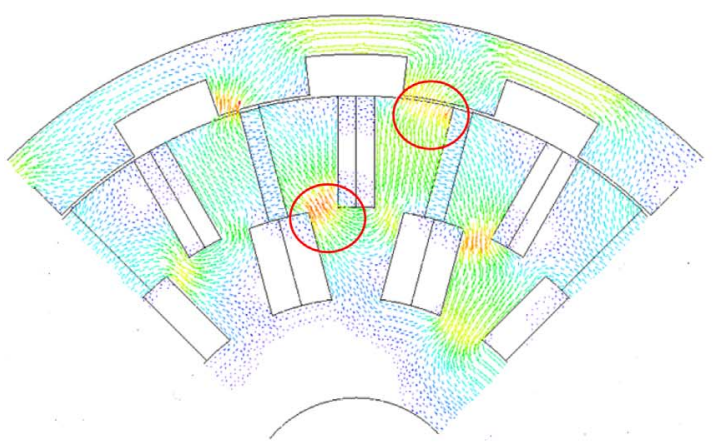

(a) $J_{e}=0 \mathrm{~A} / \mathrm{mm}^{2}, J_{a}=30 \mathrm{~A}_{\mathrm{rms}} / \mathrm{mm}^{2}$

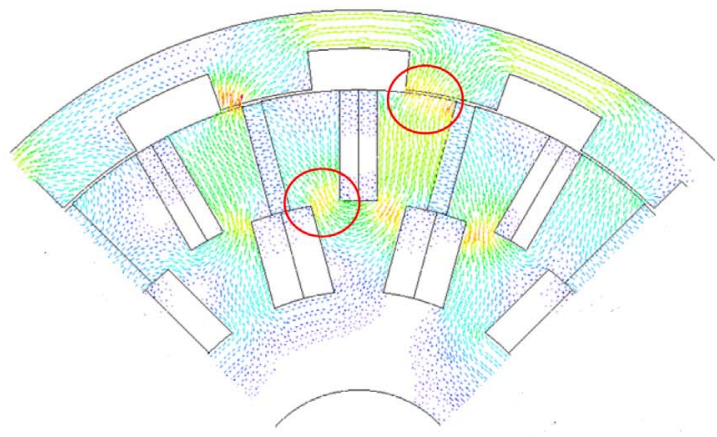

(b) $J_{e}=10 \mathrm{~A} / \mathrm{mm}^{2}, J_{a}=30 \mathrm{~A}_{\mathrm{rms}} / \mathrm{mm}^{2}$

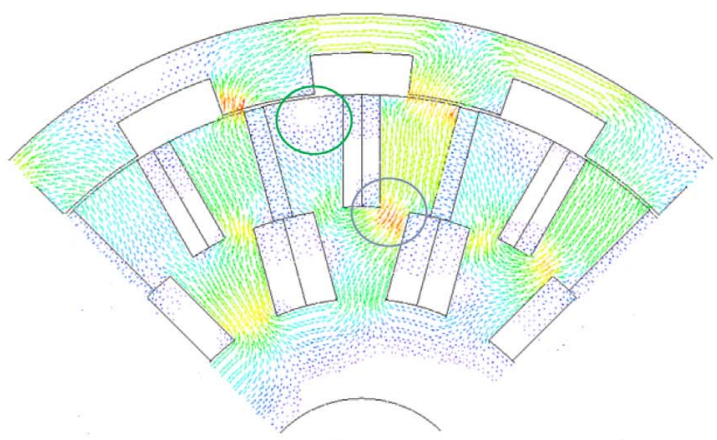

(c) $J_{e}=20 \mathrm{~A} / \mathrm{mm}^{2}, J_{a}=30 \mathrm{~A}_{\mathrm{rms}} / \mathrm{mm}^{2}$

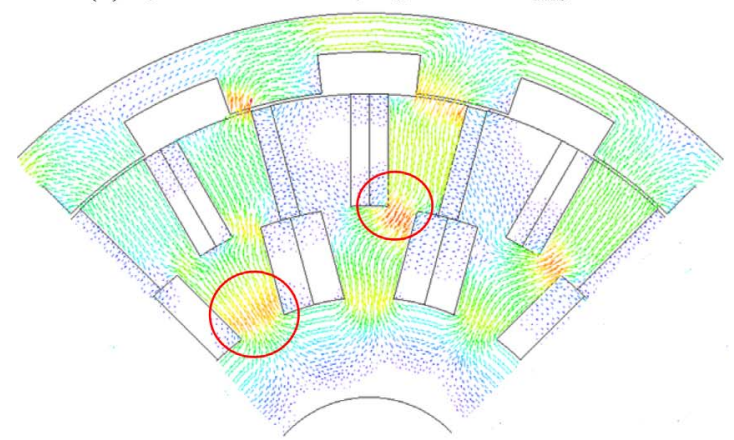

(d) $J_{e}=30 \mathrm{~A} / \mathrm{mm}^{2}, J_{a}=30 \quad \mathrm{~A}_{\mathrm{rms}} / \mathrm{mm}^{2}$

Fig. 6. (Color online) Magnetic flux distribution on quarter of the machine. of DC FEC as shown by the circled region in Fig. 6(b). Hence, when the $J_{e}$ was increased to $20 \mathrm{~A} / \mathrm{mm}^{2}$, more fluxes flow to the rotor as well as on the inner stator back yoke, resulting flux saturation between the DC FEC and armature coil slots as indicated by the blue circle in Fig. 6(c). Moreover, some of the flux from DC FEC is cancelled with the flux from the PM at the area indicated by the green circle, and the remaining fluxes are forced to flow through the inner stator back yoke. Finally, when the $J_{e}$ was set at a maximum of $30 \mathrm{~A} / \mathrm{mm}^{2}$, the fluxes are totally saturated in the region of the adjacent DC FEC slot and between the DC FEC and armature coil slots as shown by the red circle in Fig. 6(d). Therefore, the design refinement and improvement especially on the abovementioned region shall be conducted to decrease the flux saturation, hence improving the performances.

Finally, the torque productions of the original design machine at various current densities were also investigated. In this design, the torque versus DC FEC current density $J_{e}$ at various armature current densities was plotted, as shown in Fig. 7. Both the armature current and DC FEC current densities were varied from $0\left(\mathrm{~A}_{\mathrm{rms}}\right.$ or $\left.\mathrm{A}\right) /$ $\mathrm{mm}^{2}$ to $30\left(\mathrm{~A}_{\mathrm{rms}}\right.$ or $\left.\mathrm{A}\right) / \mathrm{mm}^{2}$. The graph shows that the torque increased with increasing $J_{e}$ up to a certain point. Once the torque reaches its maximum point, the torque starts to decrease when higher $J_{e}$ was applied. This pattern is almost similar for the entire condition of armature current densities.

This phenomenon validates the flux conditions discussed above in which some of the flux has saturated at a certain condition of current density. Moreover, the reduction of torque when reaching its maximum point is because of the flux cancellation between the excitation flux and armature coil flux, thus producing a much negative torque. Again, the design refinement of the distance between the DC FEC and armature coil slots and also the distance between the adjacent of the DC FEC slot should be implemented to avoid flux saturation.

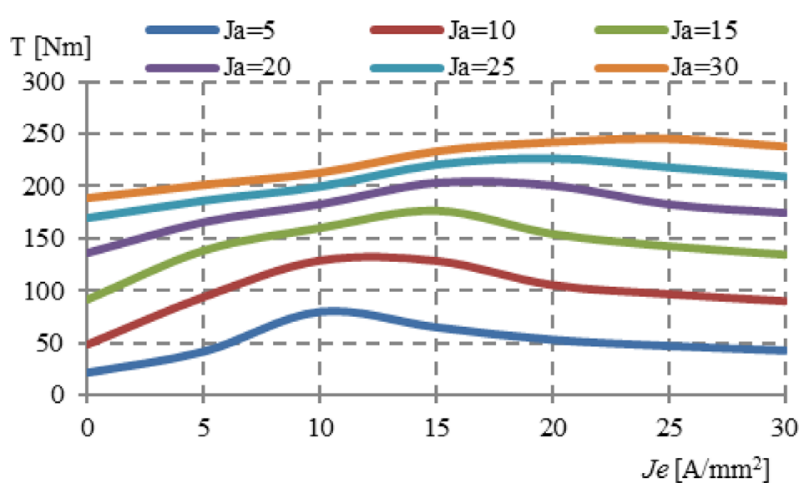

Fig. 7. (Color online) Torque versus $J_{e}$ at various $J_{a} \mathrm{~s}$. 


\section{Design Improvement and Optimization}

To overcome the highlighted problems of the original design machine, some design parameters were introduced in the stator and rotor parts as shown in Fig. 8. In general, the design parameters are divided into four groups, relating to the rotor core, PM, FEC slot, and armature coil slot. To find the optimal performances, each parameter was treated individually from $D_{1}$ to $D_{10}$ under the same volume of PM and air gap length. The inner rotor radius, $\mathrm{D}_{1}$, is the first treated parameter, which is considered as a dominant parameter to improve the torque. Once the optimal torque and power are achieved by treating $\mathrm{D}_{1}$, then $\mathrm{D}_{2}$ and $\mathrm{D}_{3}$ are adjusted until the combination of maximum torque and power is obtained. Then, the same procedure is applied to the rest of the components. The second step is carried out by updating the PM slot parameters $\mathrm{D}_{4}$ and $\mathrm{D}_{5}$, while keeping the other parameters constant. With the optimal results obtained in the second step, the FEC slot parameters of $\mathrm{D}_{6}$ and $\mathrm{D}_{7}$ are then varied in the third step. Then, the same procedure is applied for the fourth step that relates to the armature coil slot parameters of $\mathrm{D}_{8}$ and $\mathrm{D}_{9}$ once the optimal torque and power are achieved in the third step. In this step, the parameters are treated by ensuring the number of turns of armature coil, considering $N_{a}$ to be an integer number. At last, the parameter of $D_{10}$ is adjusted by keeping the same PM volume and all the parameters of $D_{1}$ to $D_{9}$. The design method is treated repeatedly by varying $D_{1}$ to $D_{10}$ until the target maximum torque and power are achieved. Finally, to allow the magnetic flux to flow easily and smoothly between the adjacent FEC slots and between the armature and FEC slots, both the armature and FEC slots shape are changed from the rectangular to trapezoidal shape. Moreover, some of the coil edges are redesigned to have a curve shape to provide optimal performances. Along the optimization process, the air gap length of the machine was kept constant at $0.8 \mathrm{~mm}$. After several cycles of optimization, the outer-rotor PMFSM with $1.0 \mathrm{~kg}$ PM successfully achieved the target performances of maximum

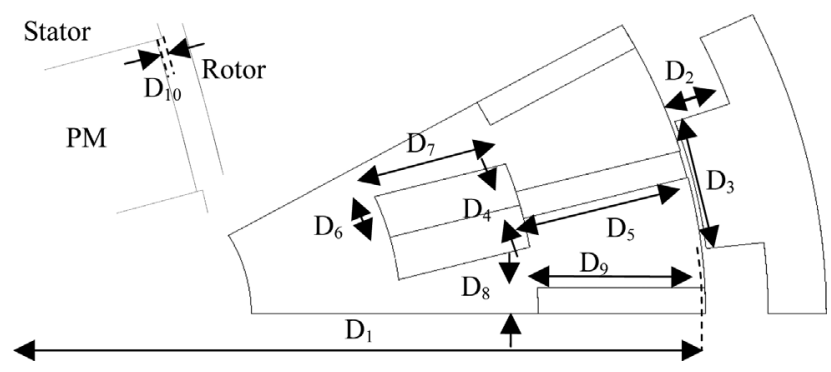

Fig. 8. Design parameters definition of $D_{1}$ to $D_{10}$.

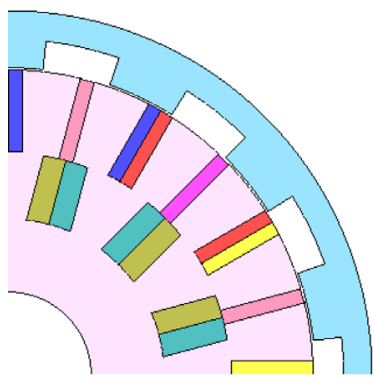

(a) Original design

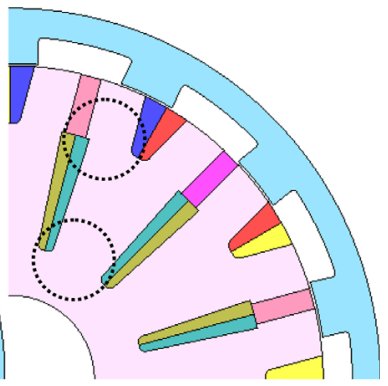

(b) Optimized design
Fig. 9. (Color online) Comparison of the original and final designs outer-rotor PMFSM with DC FEC.

torque and power.

\section{Optimized Design and Results}

\subsection{Comparison of Original and Optimized Design Machine}

A comparison of original and final designs outer-rotor PMFSM with DC FEC is shown in Fig. 9. The final design machine has a sufficient distance between the adjacent FEC slot and between the FEC and armature coil slots, allowing the magnetic flux to flow smoothly as indicated by the dotted circle in Fig. 9(b). In contrast, the flux distribution at high $J_{e}$ condition of 25 and $30 \mathrm{~A} / \mathrm{mm}^{2}$ is shown in Fig. 10. Because the spaces between the adjacent FEC slots and between the FEC slot and armature coil were increased, the magnetic flux saturation caused by higher excitation current was mitigated. Thus, the final design machine has the ability to maintain the torque production under high excitation current conditions.

\subsection{Torque Characteristics at Various Current Densi-} ties

The analysis of torque versus FEC current density at various armature current densities is shown in Fig. 11. Both the armature and FEC current densities were varied

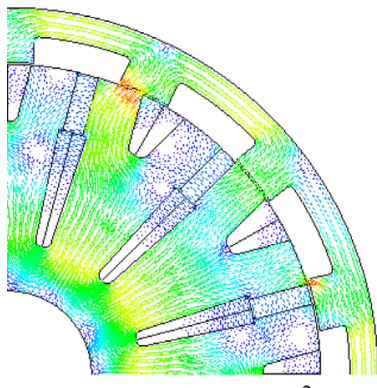

(a) $J_{e}=25 \mathrm{~A} / \mathrm{mm}^{2}$

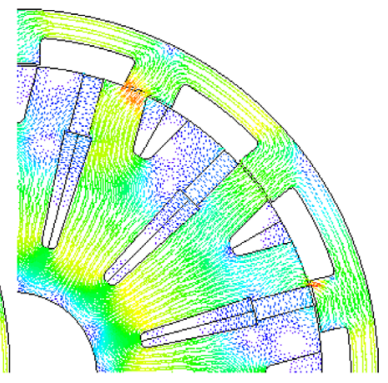

(b) $J_{e}=30 \mathrm{~A} / \mathrm{mm}^{2}$
Fig. 10. (Color online) Comparison of magnetic flux distribution at higher excitation currents. 


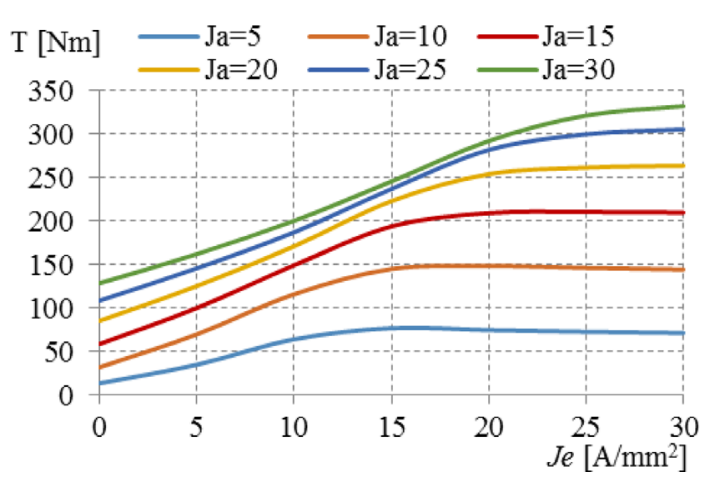

Fig. 11. (Color online) Torque versus FEC current density at various armature currents.

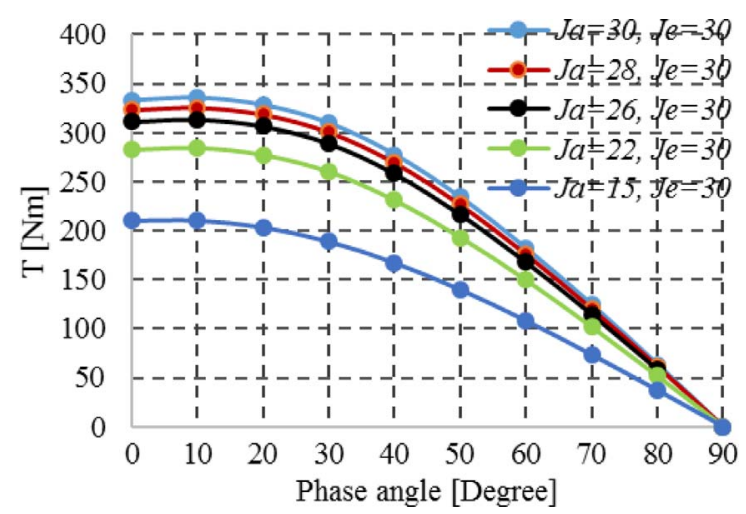

Fig. 12. (Color online) Torque-current phase angle characteristics.

up to the maximum of $30 \mathrm{~A}_{\mathrm{rms}} / \mathrm{mm}^{2}$ and $30 \mathrm{~A} / \mathrm{mm}^{2}$, respectively. It is comprehensible that an increase in the armature current density will increase the torque performance, thus a maximum torque of $332.57 \mathrm{Nm}$ was achieved at the maximum armature current and excitation current densities.

To investigate the optimal torque performance, the average torque values at various current phase angles at the maximum DC FEC current density were predicted as shown in Fig. 12. The maximum torque of $335.08 \mathrm{Nm}$ was obtained at a current phase angle of $10^{\circ}$ when both the armature and DC FEC current densities were set at 30 $\mathrm{A}_{\mathrm{rms}} / \mathrm{mm}^{2}$ and $30 \mathrm{~A} / \mathrm{mm}^{2}$, respectively.

\subsection{Torque and Power versus Speed Characteristics}

The comparison of torque versus speed characteristic of the final design outer-rotor PMFSM with DC FEC and IPMSM conventionally used in the existing HEV is shown in Fig. 13. The graph clearly shows that the final design machine produced better torque speed ranges and much higher torque capability. The maximum torque of $335.08 \mathrm{Nm}$ was achieved for the final design machine at a base speed of 4,149 r/min. In contrast, a maximum torque

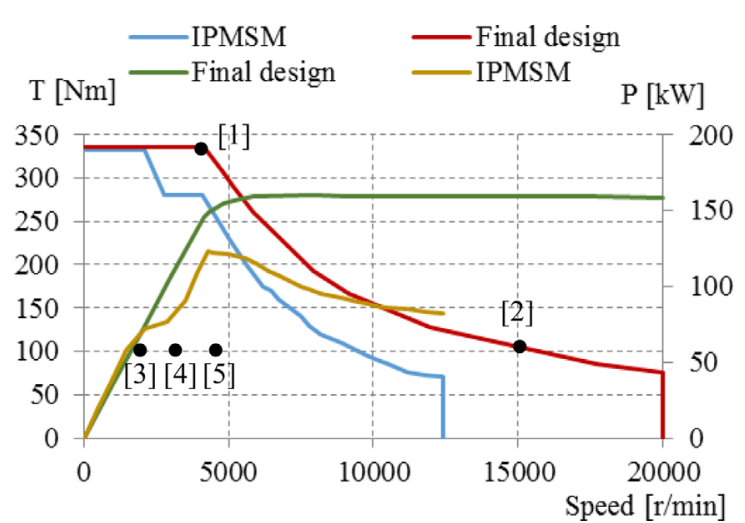

Fig. 13. (Color online) Torque and power versus speed characteristics.

of $333 \mathrm{Nm}$ at a base speed of 2,100 r/min was produced for IPMSM. The extra advantage of the final design machine is that the machine can operate up to a maximum speed of 20,000 r/min, whereas the maximum speed of IPMSM was only up to $12,400 \mathrm{r} / \mathrm{min}$.

Meanwhile, the comparisons of power versus speed characteristics between the final design machine and conventional IPMSM are also analyzed in the same graph. The graph shows that initially the power curve characteristic of IPMSM increases up to the maximum point but starts to decrease with further increase in the speed. The maximum power of IPMSM was $123 \mathrm{~kW}$ at a speed and torque of $\sim 4,600 \mathrm{r} / \mathrm{min}$ and $260 \mathrm{Nm}$, respectively, whereas for the final design machine, initially the power also increased up to a speed of 7,919 r/min and was constant in the high-speed region. The power achieved at a maximum torque of $335.08 \mathrm{Nm}$ was $145.59 \mathrm{~kW}$ at a speed of 4,149 r/min, whereas the maximum power obtained was $160.2 \mathrm{~kW}$ at a speed and torque of 7,919 r/ min and $193.17 \mathrm{Nm}$, respectively. In contrast, from the torque and power versus speed characteristic, the final design machine of the outer-rotor PMFSM with DC FEC is much better than the conventional IPMSM, because of its high and constant power in the high-speed region. Finally, at the calculated weight of $27.03 \mathrm{~kg}$ for the final design machine, the maximum torque and power densities of $12.4 \mathrm{Nm} / \mathrm{kg}$ and $5.93 \mathrm{~kW} / \mathrm{kg}$, respectively, were achieved.

\subsection{Losses and Efficiency}

The motor copper loss, iron loss, and efficiency were calculated considering the copper losses in armature and FEC windings and iron loss in all the laminated cores. The specific operating points at the base speed, high speed, and frequent operating conditions under a low load marked by No. 1 to No. 5 are shown in Fig. 13. Moreover, the detail loss analysis and motor efficiency of the 


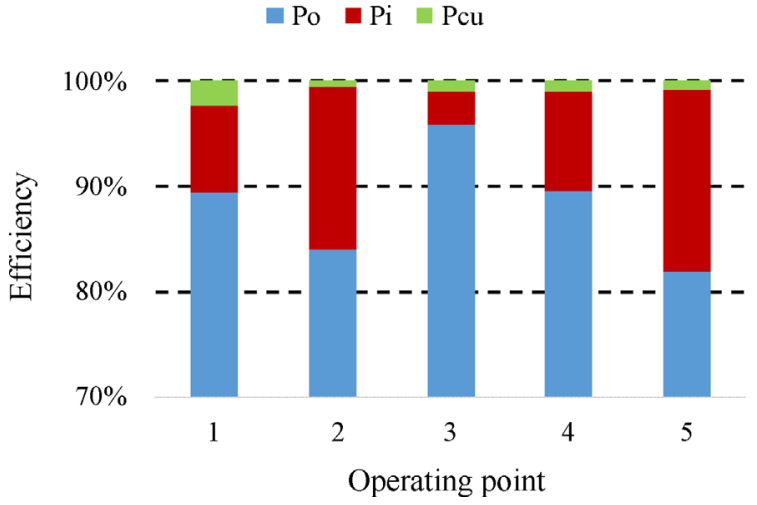

Fig. 14. (Color online) Losses and efficiency of the final design outer-rotor PMFSM with DC FEC.

final design machine are illustrated in Fig.14. The output power, iron loss, and copper loss of the machine are indicated by $P_{o}, P_{i}$, and $P_{c u}$, respectively. The machine has a high efficiency at the base speed and normal operation condition, labeled by Nos. 1, 3, and 4. However, at a high speed of $15,000 \mathrm{r} / \mathrm{min}$, the efficiency of the machine slightly decreased, because of high iron loss.

\section{Conclusions}

A comprehensive analysis of 12S-14P outer-rotor PMFSM with DC FEC for in-wheel direct drive EV was carried out. The 2D-FEA models and the optimization of several machine's parameters by the "deterministic optimization approach" to decompose the maximum output torque and power densities are discussed in details. The final design machine offers the advantages of robust rotor structure, lighter weight, flux control capability, and much higher torque and power densities. With only $1.0 \mathrm{~kg}$ of PM weight and average efficiency at a low speed operating point of $88 \%$, the proposed machine has a great potential to be applied for in-wheel drive EV.

\section{Acknowledgements}

This study was supported by the Fundamental Research Grant Scheme (FRGS), Vote No. 1508, the Ministry of Education Malaysia and Office for Research, Innovation, Commercialization and Consultancy Management (ORICC), Universiti Tun Hussein Onn Malaysia, Johor.

\section{References}

[1] V. Bucha, Journal of Atmospheric and Terrestrial Physics 53, 1161 (1991).

[2] J. King, The King Review of low-carbon cars - Part II: Recommendations for action (March 2008). Available online: www.hm-treasury.gov.uk/king.

[3] Sung-Il Kim, Sunghyuk Park; Taesang Park, Jinwoo Cho, Wonho Kim, and Seongtaek Lim, IEEE Trans. Ind. Electron. 61, 5763 (2014).

[4] C. C. Chan, IEEE Journals \& Magazines 81, 1202 (1993).

[5] Y. P. Yang and D. S. Chuang, IEEE Trans. Magn. 43, 51 (2007).

[6] Wu, L. Song, and S. Cui, IEEE Trans. Magn. 43, 438 (2007).

[7] K. M. Rahman, N. R. Patel, T. G. Ward, J. M. Nagashima, F. Caricchi, and F. Crescimbini, IEEE Trans. Ind. Appl. 42, 1185 (2006).

[8] Z. Q. Zhu and D. Howe, Proc. IEEE 95, 746 (2007).

[9] D. Dorrell, L. Parsa, and I. Boldea, IEEE Trans. Ind. Electron. 61, 5693 (2014).

[10] K. T. Chau, C. C. Chan, and Chunhua Liu, IEEE Trans. Ind. Electron. 55, 2246 (2008).

[11] Y. Amara, E. Hoang, M. Gabsi, and M. Lecrivain, Euro. Trans. Electron. Power 15, 497 (2005).

[12] C. Pollock, H. Pollock, R. Borron, J. R. Coles, D. Moule, A. Court, and R. Sutton, IEEE Trans. Ind. Appl. 42, 1177 (2006).

[13] M. J. Jin, Y. Wang, J. X. Shen, P. C. K. Luk, W. Z. Fei, and C. F. Wang, IET Electric Power Appl. 4, 647 (2010).

[14] H. Pollock, C. Pollock, R. T. Walter, and B. V. Gorti, Proc. IEEE Ind. Appl. Soc. Annu. Meeting (2003) pp. 1451-1457.

[15] E. Sulaiman, T. Kosaka, and N Matsui, IEEE Trans. Magn. 47, 4453 (2011).

[16] J. T. Chen and Z. Q. Zhu, IEEE Trans. Energy Conversion 25, 293 (2010).

[17] Y. Wang and Z. Deng, IEEE Trans. Magn. 48, 2518 (2012).

[18] Y. Tang, J. J. H. Paulides, T. E. Motoasca, and E. A. Lomonova, IEEE Trans. Magn. 48, 3583 (2012).

[19] E. Sulaiman, T. Kosaka, and N. Matsui, Renewable and Sustainable Energy Reviews 34, 517 (2014).

[20] Y. Wang, M. J. Jin, J. Shen, W. Z. Fei, and P. C. K. Luk, Energy Conversion Congress and Exposition (ECCE) (2010) pp. 1723-1730.

[21] W. Fei, P. Chi K. Luk, J. X. Shen, Y. Wang, and M. Jin, IEEE Trans. Ind. Appl. 48, 1496 (2012).

[22] M. Z. Ahmad, E. Sulaiman, Z. A. Haron, and F. Khan, Applied Mechanics and Materials Journal 660, 836 (2014). 